\title{
Design de produto inclusivo: auxiliando na comunicação de criança com espectro autista
}

\author{
Comprehensive product design: assisting in communication with autistic spectrum
}

PINTO, Ana Claudia Gaicoski; Mestre em Engenharia de Materiais e Processos de Fabricação; Universidade Luterana do Brasil - ULBRA Carazinho

anag.pinto@yahoo.com.br

ZORZETTO, Júlia; Graduanda em Design; Universidade Luterana do Brasil - ULBRA Carazinho juliademarcozorzetto@hotmail.com

CONCATTO, Luana; Graduanda em Design; Universidade Luterana do Brasil - ULBRA Carazinho luanaconcatto43@gmail.com

PINHEIRO, Thais; Graduanda em Design; Universidade Luterana do Brasil - ULBRA Carazinho thaisbuenopinheiro4@gmail.com

\section{Resumo}

Este projeto de pesquisa trata do desenvolvimento de um conceito de brinquedo, para criança com espectro autista, e busca em suas formas, cores e simbologia, auxiliar na comunicação do público alvo. Tendo em vista que nos últimos anos, o mercado de brinquedos tem tido um considerável crescimento, porém, ao mesmo tempo, notou-se uma escassez na oferta de produtos destinados a esse público, bem como profissionais para desenvolvê-los, desse forma, o design tem os requisitos necessários para suprir essa necessidade. Para o desenvolvimento de tal projeto utilizou-se as metodologias de Baxter (2000), Brown (2010), a fim de projetar um produto inovador e que atenda aos requisitos dos usuários. Por fim, os resultados alcançados demonstra a interação entre os métodos projetuais e o design inclusivo, buscando atender as necessidades e fornecer um produto diferenciado que auxilie nas atividades da criança com espectro autista.

Palavras Chave: cognição; criança; autismo e inclusão.

\section{Abstract}

This research project deals with the development of a toy concept, for children with autism spectrum, and search in their forms, colors and symbology, to assist in the communication of the target audience. In view of the fact that in recent years the toy market has experienced considerable growth, but at the same time there has been a shortage in the supply of products for this public, as well as professionals to develop them, thereby design has the necessary requirements to meet this need. For the development of such a project we used the methodologies of Baxter (2000), Brown (2010), in order to design an innovative product that meets the 
requirements of the users. Finally, the results show the interaction between the design methods and the inclusive design, aiming to meet the needs and provide a differentiated product that assists in the activities of the autistic spectrum child.

Keywords: cognition; child; autism and inclusion.

\section{Introdução}

Através desse artigo pretende-se apresentar o projeto de um brinquedo, com objetivo de uma nova possibilidade e auxílio no processo de desenvolvimento cognitivo de crianças com espectro autista (TEA), promovendo uma alternativa de apoio, através de metodologias assistivas, para pais e professores na interação com crianças com TEA, o projeto teve como público alvo uma criança, sexto masculino, com idade de 3 anos. Porém antes de apresentar questões relativas ao projeto desenvolvido, se fazem necessárias algumas definições relacionadas ao Design.

Em seu livro Criatividade e Design, Gomes (2011), baseado em Bruce Archer (1966), apresenta três grandes áreas do conhecimento que se relacionam de forma intrínseca com o Desenho Industrial, são elas: Área das Ciências, Área das Humanas e Área dos Desenhos, sendo esta última subdividida em: Desenho Espontâneo, Desenho Artístico e Desenho Industrial. Contido no Desenho Industrial encontra-se ainda mais três divisões, são elas: Desenho Expressional, Desenho Operacional e Desenho Projetual, ao ponto que, este último, subdivide-se em desenho para de ambiente, de comunicação e de artefato, este último sendo foco do presente trabalho.

Em 1977, Joaquim Redig apresentou a definição que foi reforçada em 2005, e que viria a se tornar uma das principais definições para esta importante atividade profissional, dizia:

“Desenho Industrial (Design) é o equacionamento simultâneo de fatores ergonômicos, perceptivos, antropológicos, tecnológicos, econômicos e ecológicos, no projeto dos elementos e estruturas físicas necessárias à vida, ao bem estar e/ou a cultura do homem" (REGIG, 2005).

Gomes, por exemplo, relata na apresentação do livro Desenhante: Pensador do Desenho, de Nigel Cross (2004), que, autores como o britânico Bruce Archer, em 1974 já se referia ao Designer como: "alguém que formula uma prescrição para artefatos ou sistemas de produto, á luz de todas as relevantes considerações funcionais, e requisitos construtivos, econômicos, mercadológicos, ergonômicos e estéticos".

Outra importante definição foi apresentada em 1996, com o Projeto de Lei no 1.965, que visava regulamentar a profissão no Brasil, se referiu ao Design como:

uma atividade especializada de caráter técnico-científico, criativo e artístico, com vistas à concepção e desenvolvimento de projetos de objetos e mensagens visuais que equacionem sistematicamente dados ergonômicos, tecnológicos, econômicos, sociais, culturais e estéticos, que atendam concretamente às necessidades humanas (WOLFF, 2006)

Embora se perceba a influência dos Fatores Projetuais na definição de Design no Projeto de Lei, pode-se também perceber a ausência de termos como: Sustentabilidade, ecologia, "equacionamento simultâneo", bem como "sistemas", ou seja, a definição referencia o desenvolvimento de projetos de objetos (artefatos) e mensagens visuais (comunicação), omitindo, inclusive o termo "ambiente". 
A falta de uma visão mais abrangente do Design é contemplada na definição do ICSID (International Council of Societies of Industrial Design):

\begin{abstract}
Design é uma atividade criativa cujo propósito é estabelecer as qualidades multi-facetadas de objetos, processos, serviços e seus sistemas de ciclos de vida. Assim, Design é o fator central da humanização inovadora das tecnologias e o fator crucial das trocas econômicas e culturais. [...] Design trata de produtos, serviços e sistemas concebidos através de ferramentas, organizações e da lógica introduzidas pela industrialização - não somente quando são produzidos em série. (ICSID, 2000)
\end{abstract}

Nota-se que por duas vezes em sua definição, a ICSID referencia o Design de Produtos, Serviços e Sistemas, privilegiando o caráter multi/interdisciplinar da atividade profissional.

Após introduzidos os devidos conceitos, o presente artigo irá desenvolver o tema, design de produto inclusivo: auxiliando na comunicação de criança com espectro autista, com base em uma estrutura que possui em seu cerne o item Referencial Teórico abordando temas como: Produtos Industriais; Design e Inovação; Design Inclusivo e Autismo. Na sequência apresenta-se o projeto desenvolvido com base em elementos metodológicos descritos por autores como Baxter (1998), Design Thinking (2010), ao final, o item Considerações Finais.

\title{
2 Referencial Teórico
}

Como ponto de partida da revisão de literatura do presente artigo, tomou-se como norte compreender e esclarecer a atuação do design no projeto de produto, bem como a sua conotação. Com a evolução do mercado industrial, a tecnologia cada vez mais presente, muitas palavras passaram a fazer parte do nosso cotidiano, dentre elas se destaca o design, muito usado para fazer associação a um produto ou marca.

A cerca disso Löbach comenta que "as empresas industriais utilizam cada vez mais o conceito de design na publicidade ou incluem a palavra design na denominação da própria empresa". (LÖBACH, 2001, p.11).

Partindo desse pensamento, o design é responsável pela determinação das características funcionais, estruturais, estéticas e formas de artefatos ou de um conjunto de produtos (artefatos) para produção em série. Ele deve desenvolver um método de trabalho que torne possível dominar um conjunto de conhecimentos e informações de ordem técnica, ergonômica, psicológica, mercadológica, estética, econômica e cultural, gerando alternativas que permitam encontrar uma solução final para o produto. (CUNHA, 2003).

\subsection{Produtos Industriais}

Produtos industriais, no entendimento de Löbach (2001, p.38), "são objetos destinados a cobrir determinadas necessidades e são produzidos de forma idêntica para um grande número de pessoas".

Em um mercado cada vez mais competitivo, onde há a necessidade de ressaltar um produto (artefato) (ou seja, chamar a atenção) se incorpora a função estética como fator de decisão do comprador. A função estética em muitos casos é mais atuante no ato da compra que as funções práticas de um produto industrial, das quais só serão percebidas na maioria das vezes quando se chega em casa. (LÖBACH, 2001). 
Sobre a forma dos produtos industriais Redig (2005, p. 20) relata que "forma é o meio de expressão do designer, enquanto o homem é o destinatário do produto resultante do design, a forma é a expressão física desse mesmo produto".

De acordo com Löbach (2001) existem quatro categorias de produtos industriais distintas em produtos de consumo, produtos para uso individual, produtos para uso de determinados grupos e produtos para uso indireto. Entendem-se como produtos de consumo aqueles que satisfazem a uma necessidade fundamental do homem, como produtos alimentícios, de limpeza, como creme dental e sabonetes. Produtos para uso individual são produtos industriais usados exclusivamente por uma determinada pessoa, como canetas, óculos ou relógios de pulso. Produtos para uso de determinados grupos pertencem os produtos que serão utilizados por um pequeno grupo de pessoas que se conhecem uma das outras, como refrigeradores, mobiliário, fogão ou televisor. Produtos para uso indireto são produtos industriais que permanecem ocultos, que são utilizados diretamente pelos consumidores, como turbinas de geração de energia, rolamentos, esferas e parafusos.

\subsection{Design e Inovação}

Design e Inovação representam conceitos interdependentes, pois a visão sistêmica inerente a formação dos designers somada ao pensamento complexo abordado nos estudos sobre inovação configuram uma poderosa estratégia de diferenciação e sustentabilidade organizacional. Como diz o legendário Samurai Miyamoto Musashi, "em estratégia", é importante ver o que está distante como se estivesse perto e o que está perto como se estivesse distante. Esta visão sistêmica é defendida por autores como Capra (1996), Morgan (1996) e Maturana (1995) que relatam que não podemos relacionar fatos de maneira mecanicista, como um relógio, repleto de mecanismos independentes que servem apenas para compor o todo, quando o todo deveria compor cada parte.

Segundo Bezerra (2010), pode-se pensar o estudo da complexidade dividido em três grandes ondas de interesse. A primeira ocorreu logo após a Primeira Guerra Mundial, os estudos se preocuparam com o conceito de que o todo é maior que a simples soma das partes. A segunda onda ocorreu depois da Segunda Guerra Mundial e teve como mote os estudos em autoorganização (homeostase). A terceira onda é marcada pelo surgimento dos computadores e pelas imensuráveis possibilidades de mensuração de novas teorias.

Tidd (2008) relata que o termo inovação vem do latim innovare, que significa "fazer algo novo" e define inovação como um processo de fazer de uma oportunidade uma nova ideia e de colocá-la em uso da maneira mais ampla possível. Tidd ainda apresenta outras definições, como a da Unidade de Inovação do Reino Unido (2004): “Inovação é a exploração de novas ideias.

Coral (2008), referencia o Manual de Oslo (OECD, 2005, p. 46; FINEP, 2006, p. 55), que define inovação como: "implementação de um produto (bem ou serviço) novo ou significativamente melhorado, ou um processo, ou um novo método de marketing, ou um novo método organizacional nas práticas de negócios, na organização do local de trabalho ou nas relações externas".

Conforme Freeman (1982) apud Tidd (2008), a inovação industrial inclui técnica, design, fabricação, gerenciamento e atividades comerciais pertinentes ao marketing de um produto novo 
(ou incrementado) ou do primeiro uso comercial de um processo ou equipamento novo (ou incrementado). O autor ainda define que a inovação pode ser classificada quanto a: Natureza (produto, processo e negócio); Forma (Tecnológica e Organizacional); Abrangência (Empresa, Mercado ou Mundo); Intensidade (Incremental, Semi-radical e Radical); Propósito (Ocasional ou Intencional).

"O design motiva a inovação, a inovação dá poder à marca, a marca constrói a fidelidade e a fidelidade sustenta os lucros. Se você deseja lucro a longo prazo, não comece com a tecnologia, comece com o Design" (NEUMEIER, 2010). O autor ainda descreve que:

\begin{abstract}
Quando você pergunta aos CEO's o que mais Ihes tiram o sono, a maioria das respostas vão ser que é o valor das ações. Quando você questiona a ele o que orienta a cotação das ações a resposta muitas vezes é o crescimento de receitas. Sempre que você indaga sobre o que promove o crescimento das receitas, a resposta talvez seja: A inovação, ou um olhar vazio, um "branco". E quando você questiona as motivações da inovação, poucos desses CEO's entendem que a inovação brota da cultura colaborativa e se você questionar sobre o que gera esta cultura, um número ainda menor deles irão dizer que a liderança visionária é a chave para o incentivo de uma cultura de inovação.
\end{abstract}

Neumeier (2010) defende que a inovação em gestão que vai destronar o Seis Sigma é o pensamento focado em Design (design thinking). Esse modo de pensar assumirá o controle dos departamentos de marketing, tomará posse dos laboratórios de pesquisa e desenvolvimento, transformará processos e começará a ignição da cultura. $O$ autor expõe ainda que essa inovação criará um efeito rebote, que alinhará as finanças a criatividade, e entrará em Wall Street com força o bastante para mudar as regras dos investimentos.

\title{
2.3 Design Inclusivo
}

De acordo com Simões, Bispo (2006) trata-se o design inclusivo como a abordagem de projetos de produtos e ambientes, que possam ser utilizados por pessoas de todas as capacidades, tendo como principal objetivo contribuir, para a não discriminação e inclusão social de todas as pessoas.

O conceito de Design Inclusivo está relacionado diretamente ao Desenho Universal, onde segundo Ferrés (2005) o desenvolvimento de produtos e ambientes permitem a utilização destes, independentemente da idade ou condição física, pelo maior número de pessoas possíveis, tornando-se fundamental possibilitar a qualquer pessoa, através do design inclusivo ou universal, a praticar ações essenciais do seu cotidiano.

Ao que refere-se aos princípios do Design Universal, o "Center for Universal Design College of Design" da Universidade do Estado da Carolina do Norte, apresenta os seguintes princípios:

Princípio 1: Uso equitativo, deve garantir a todos os utilizadores a mesma possibilidade de utilização, deve ser atrativo a todos, sem estigmatizar pessoas com dificuldades ou deficiências. Princípio 2: Flexibilidade no uso, deve permitir escolher a forma de utilização adequada, deve dar a possibilidade de ser adaptável, promovendo ao mesmo tempo a precisão de utilização.

Princípio 3: Uso simples e intuitivo, deve ser de compreensão fácil, mesmo por utilizadores inexperientes, com dificuldade de desempenho ou comunicação. Deve estar ao nível das expectativas do utilizador, não deve ser complexo. 
Princípio 4: Informação perceptível, a informação necessária à sua utilização deve ser independentemente das suas dificuldades ou condições de uso.

Princípio 5: Tolerância ao erro, deve minimizar as consequências negativas resultantes de possíveis erros de utilização, acidentais ou não intencionais, camuflar os fatores que levam ao erro, divulgar os possíveis riscos.

Princípio 6: Baixo esforço físico, deve possibilitar a sua utilização com o mínimo de dispêndio de energia, com um baixo esforço físico e minimizando as operações repetitivas.

Princípio 7: Tamanho e espaço para uso e aproximação adequados, devem ser acautelados os espaços, a visibilidade e o tamanho necessários à sua utilização visível, inteligível e compreensível a todos os utilizadores, por qualquer pessoa, independentemente das suas dificuldades de mobilidade, volume, altura ou postura. (CENTER FOR UNIVERSAL DESIGN, 2012)

Compreende-se, portanto que, quando os conceitos de design inclusivo ou universal referem-se a todas as pessoas, isto significa que um projeto de produto ou ambientes deverá ser acessível a todos as pessoas, independente de idade ou gênero, em qualquer local do mundo. Sobretudo, em virtude da diversidade de questões envolvidas na relação usuário-produto, levando em consideração condições físicas, cognitivas, sociais e culturais, esses princípios e/ou objetivos tornam-se inviáveis de ser alcançados na sua totalidade, porém, deve-se trabalhar com os princípios como meta, tendo como objeto alcançar o máximo de usuários, pois o design inclusivo propiciará autonomia, independência e segurança no uso de produtos e ou ambientes.

Dessa forma, observa-se que na criação de produtos e ambientes deve-se levar em conta o conhecimento das necessidades das pessoas que irão utilizar, para isso é necessário que o designer centre a sua atenção no usuário ao longo do desenvolvimento do produto, buscando identificar dificuldades, necessidades e limitações.

\subsection{Autismo}

Etimologicamente a palavra autismo tem sua origem no grego "autos" que significa "si mesmo", (SILVA; PERANZONI,2012). Muitos estudos e pesquisas sobre o autismo surgiram desde 1911 em diferentes áreas do conhecimento, como na psicanálise, pedagogia, biologia, genética e de acordo com Aguiar e Alonso (2015) o autismo é uma doença definida como um transtorno, denominada Transtorno do Espectro Autista (TEA).

Ainda conforme Aguiar e Alonso (2015) o diagnóstico não é simples, é mais comum em meninos, quando presente em meninas se manifesta de forma menos grave, pode surgir nos primeiro três anos de vida, através do atraso ou desenvolvimento anormal da fala e na interação social.

De acordo com a quinta edição do Manual Diagnóstico e Estatística dos Transtornos Mentais (DSM-5, 2013, p. 50), da Associação Americana de Psiquiatria, os critérios para obtenção do diagnóstico são:

Déficits persistentes na comunicação social e interação social através de vários contextos, como manifestado pelos seguintes elementos, no momento ou pela história:

1. Os déficits na reciprocidade sócio emocional, que vão, por exemplo, do social, anormal, abordagem e fracasso do normal conversa de volta-e-vem; a partilha reduzida de interesses, emoções, ou afeto; a incapacidade de iniciar ou responder às interações sociais;

2. Os déficits em comportamentos comunicativos não verbais utilizados para a interação social, que vão, por exemplo, de mal a comunicação verbal e não verbal integrada; a 
anormalidades no contato visual e linguagem corporal ou déficits na compreensão e uso de gestos: para uma total falta de expressões faciais e comunicação não-verbal.

3. Os déficits no desenvolvimento, manutenção e compreensão das relações, que vão, por exemplo, de dificuldades de ajuste de comportamento para atender diversos contextos sociais; a dificuldades na partilha de jogo imaginativo ou em fazer amigos; a ausência de interesse em pares.

Muitos são os sintomas da criança com TEA, podendo mencionar dentre eles quando ainda criança não há interação com a mãe no momento da amamentação, são obcecados por rotina, detalhes e certos objetos, também possuem movimentos estereotipados, ou seja, repetitivos, que quando ansiosos, eufóricos ou irritados podem se intensificar. (ALONSO; AGUIAR,2015)

No entanto, cada criança apresenta uma forma de autismo com características individuais, próprias, apesar de comportamentos e dificuldades comuns nas crianças com TEA, poderão variar na mesma criança no decorrer do seu desenvolvimento.

Nesse sentido, reafirma-se a necessidade de crianças com TEA serem estimuladas durante o seu desenvolvimento e aprendizagem, e isso pode ser auxiliado através de intervenções do design no projeto de produtos e ambientes que estimulem a aprendizagem, integração e auxiliem a atenuar as dificuldades já mencionadas.

\section{Projeto de brinquedo para criança com espectro autista - TEA}

Posteriormente a revisão bibliográfica inicia-se o desenvolvimento de projeto de produto/brinquedo para criança com TEA, que resultará em uma nova solução concreta, sendo ela o objetivo de entregá-la ao usuário para sua utilização.

Baseando-se na metodologia Baxter (1998) e Design Thinking, de Tim Brown (2010), foi realizado o briefing com o público alvo do projeto, incluindo criança e mãe, onde foi realizado através de um questionário a mãe e observação assistemática da criança, que serviram para a geração e seleção de ideias do produto.

Logo após, analisou-se as diversas dificuldades percebidas no indivíduo em questão. Os critérios de análise dividem-se em idade e desenvolvimento cognitivo e motor, meio em que vive e gostos pessoais. Avaliando os critérios citados optou-se pela resolução do problema de comunicação. Realizou-se pesquisas sobre a importância da comunicação de crianças com TEA, diferenças entre comunicações (verbal e não-verbal), o viés da estimulação que envolve principalmente os profissionais de fonoaudiologia e psicopedagogia. As características de falha na comunicação são pertinentes entre todos os casos de TEA, o que fundamentou o projeto para a escolha deste tema, que embasou-se nos estudos da autora Kwant (2017).

Para uma melhor compreensão sincrônica de produtos avaliou-se as opções que são disponibilizadas no mercado, conforme Figura 1. 
Figura 1 - análise sincrônica de produtos

\begin{tabular}{|c|c|c|c|c|c|c|c|c|c|c|}
\hline PRODUTO & VALOR & MATERIAL & COR & $\begin{array}{l}\text { ESPECIAL P/ } \\
\text { AUTISTAS }\end{array}$ & TAMANHO & $\begin{array}{l}\text { FORMA DE } \\
\text { VENDA }\end{array}$ & FUNÇÃO & ESTIMULO & DIFICULDADE & OBSERVAÇÕES \\
\hline & 69,99 & $\begin{array}{l}\text { plástico } \\
\text { alimentado } \\
\text { bateria }\end{array}$ & $\begin{array}{c}\text { diversas } \\
\text { contrastantes }\end{array}$ & não & 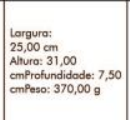 & $\begin{array}{c}\text { internet } \\
\text { e- commerce }\end{array}$ & Robô de atividades & $\begin{array}{c}\text { Cores, sons, } \\
\text { formase texturas } \\
\text { que estimulam } \\
\text { obebê }\end{array}$ & $\begin{array}{l}\text { pequeno } \\
\text { e muitos } \\
\text { estimulos }\end{array}$ & $\begin{array}{c}\text { muitos } \\
\text { estimulos } \\
\text { ruim } \\
\text { bateria }\end{array}$ \\
\hline & $\begin{array}{l}\text { caro } \\
\text { pede } \\
\text { email }\end{array}$ & $\begin{array}{c}\text { plástico } \\
\text { tela } \\
\text { com entradas } \\
\text { tomada }\end{array}$ & $\begin{array}{c}\text { diversas } \\
\text { contrastantes }\end{array}$ & universal & $\begin{array}{l}\text { grande } \\
\text { mesa } \\
4 \text { pés }\end{array}$ & $\begin{array}{c}\text { lojate } \\
\text { listribuidora } \\
\text { playtable }\end{array}$ & \begin{tabular}{|l|} 
mesa digitial, interativa \\
e multidisciplinar para \\
educar e divertir \\
crianças a partir \\
de 3 anos de idade.
\end{tabular} & 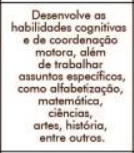 & $\begin{array}{l}\text { preço } \\
\text { alto }\end{array}$ & $\begin{array}{c}\text { adquire } \\
\text { mais iogos } \\
\text { pelo site } \\
\text { precesos variam } \\
\text { de } 89,90 \\
\text { a } 299,00\end{array}$ \\
\hline & $\$ 12.75$ & tecido & super colorido & $\operatorname{sim}$ & medio & 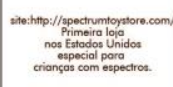 & alfabetização & $\begin{array}{l}\text { Blocos de } \\
\text { assentamento } \\
\text { de alfabeto }\end{array}$ & 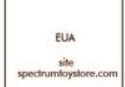 & Fatia DPUUCGGAO \\
\hline & $\mathrm{R} \$ 31,90$ & $\begin{array}{c}\text { papel } \\
\text { para fazer } \\
\text { as atividades } \\
\text { artesanato }\end{array}$ & $\begin{array}{c}\text { colorido } \\
\text { configuração } \\
\text { simples }\end{array}$ & não & $\begin{array}{l}\text { caderno } \\
\text { revista }\end{array}$ & 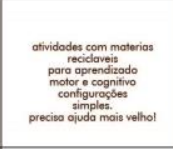 & artesanato & \begin{tabular}{|c|} 
cognitvo \\
motor \\
compartilha \\
artesanato
\end{tabular} & $\begin{array}{c}\text { precisa } \\
\text { auxilio de } \\
\text { outra } \\
\text { pessoa }\end{array}$ & $\begin{array}{l}\text { caro } \\
\text { pelo que vail } \\
\text { sem } \\
\text { algo mais... }\end{array}$ \\
\hline & $R \$ 35,00$ & $\begin{array}{c}\text { plastico } \\
\text { c/ } 5 \text { botoes } \\
\text { com ações \# }\end{array}$ & $\begin{array}{l}\text { cores coloridas } \\
\text { ou sobria }\end{array}$ & sim & $\begin{array}{c}\text { pequeno } \\
\text { cabe bolso }\end{array}$ & $\begin{array}{l}\text { mercado livre } \\
\text { e-commerce }\end{array}$ & $\begin{array}{c}\text { Fidget } \\
\text { Anti Stress Ansiedade } \\
\text { Tea Autismo Tdah }\end{array}$ & $\begin{array}{c}\text { acalmar } \\
\text { diminui tics e } \\
\text { estereotipias, }\end{array}$ & $\begin{array}{c}\text { peça } \\
\text { pequena }\end{array}$ & $\begin{array}{l}\text { caro } \\
\text { valor }\end{array}$ \\
\hline & RS 12,94 & borracha & $\begin{array}{l}\text { cores coloridas } \\
\text { ou sobria }\end{array}$ & $\operatorname{sim}$ & medio & $\begin{array}{l}\text { mercado livre } \\
\text { e-commerce }\end{array}$ & $\begin{array}{c}\text { Antistress Bolo De } \\
\text { Uva Autismo }\end{array}$ & \begin{tabular}{|c|} 
acalmar \\
diminui tics e \\
estereotipias,
\end{tabular} & material & acessivel \\
\hline & R\$16,61 & plástico & $\begin{array}{l}\text { cores primarias } \\
\text { preto }\end{array}$ & $\operatorname{sim}$ & $\begin{array}{c}\text { pequeno } \\
\text { cabe bolso }\end{array}$ & $\begin{array}{l}\text { mercado livre } \\
\text { e-commerce }\end{array}$ & $\begin{array}{l}\text { Brinquedos } \\
\text { EDC O }\end{array}$ & 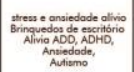 & $\begin{array}{c}\text { peça } \\
\text { pequena }\end{array}$ & acessivel \\
\hline & US $\$ 0.1-3$ & plástico & $\begin{array}{l}\text { cores coloridas } \\
\text { ou sobria }\end{array}$ & $\operatorname{sim}$ & $\begin{array}{c}73^{*} 65^{*} 77 \mathrm{~mm} \\
\text { medio }\end{array}$ & $\begin{array}{c}\text { alibaba } \\
\text { e-commerce }\end{array}$ & $\begin{array}{l}\text { Brinquedos } \\
\text { EDC O }\end{array}$ & 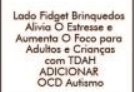 & gostei & $\begin{array}{c}\text { peça } \\
\text { pequena } \\
\text { montagem }\end{array}$ \\
\hline & $R \$ 19,86$ & plástico & cores coloridas & não & $\begin{array}{c}\text { pequeno } \\
\text { cabe bolso }\end{array}$ & $\begin{array}{c}\text { alibaba } \\
\text { e-commerce }\end{array}$ & $\begin{array}{l}\text { Brinquedos } \\
\text { EDC } 0\end{array}$ & 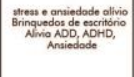 & $\begin{array}{c}\text { peça } \\
\text { pequena }\end{array}$ & $\begin{array}{l}\text { sem } \\
\text { algo mais... }\end{array}$ \\
\hline & us s155.25.5 & $\begin{array}{c}\text { sólidos de madeira } \\
\text { (madeira compensada } \\
\text { ou MDF ou outros) } \\
\text { plastico }\end{array}$ & cores coloridas & $\operatorname{sim}$ & medio & $\begin{array}{c}\text { alibaba } \\
\text { e-commerce }\end{array}$ & $\begin{array}{l}\text { Brinquedos } \\
\text { crianças com } \\
\text { autismo montor } \\
\text { sensor }\end{array}$ & 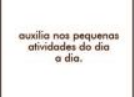 & $\begin{array}{c}\text { material } \\
\text { fazer todo de } \\
\text { madeira }\end{array}$ & acessivel \\
\hline & $\$ 27.99$ & $\begin{array}{c}\text { sólidos de madeira } \\
\text { (madeira compensada } \\
\text { ou MDF ou outros) } \\
\text { borracha }\end{array}$ & cores coloridas & $\operatorname{sim}$ & medio & $\begin{array}{c}\text { amazon } \\
\text { e-commerce }\end{array}$ & $\begin{array}{l}\text { Brinquedos } \\
\text { crianças com } \\
\text { autismo. }\end{array}$ & 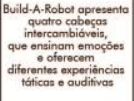 & gostei & $\begin{array}{l}\text { ccaro } \\
\text { valor?? }\end{array}$ \\
\hline- & $\$ 79,85$ & $\begin{array}{c}\text { sólidos de madeira } \\
\text { (madeira compensada } \\
\text { ou MDF ou outros) } \\
\text { borracha }\end{array}$ & cores coloridas & não & $\begin{array}{c}\text { grande } \\
\text { estatura } \\
\text { criança } \\
3 \text { a } 5 \text { anos }\end{array}$ & $\begin{array}{c}\text { amazon } \\
\text { e-commerce }\end{array}$ & $\begin{array}{l}\text { Brinquedos } \\
\text { e carinho } \\
\text { ensina a andar }\end{array}$ & \begin{tabular}{|c|} 
Brinquedos \\
crianças bebês \\
estimulaçāo \\
motora \\
fina e grossa \\
caminhar
\end{tabular} & gostei & $\begin{array}{l}\text { caro } \\
\text { valor?? }\end{array}$ \\
\hline
\end{tabular}

Fonte: adaptado (2017)

Avaliando-se os produtos pesquisados, assim como briefing e pesquisa sombra, teve-se insights da maneira de como projetar o produto, sua funcionalidade, que foi definida sendo a brincadeira, que utiliza de bases avaliadas importantes no estimulo da comunicação, além disso examinou-se o que é melhor para o usuário. Um dos pilares para a geração de ideias sobre o conceito do produto foram os seguintes aspectos: observar, analisar a interação da criança com 
cada objeto, desconstruir, pensar em outras maneiras de brincar com o objeto que não seja a clássica, afeto, entrar na brincadeira dela com elementos afetivos, como entonação de voz e gestos corporais, esperar, durante a atividade encontrar o momento ideal para criar expectativa na criança dando espaço para ela entrar na brincadeira, este é o passo mais difícil pois é necessário cativar a atenção dela por um período maior de tempo, e conectar, quando a criança percebe o interesse de quem está se relacionando com ela, pela forma com que ela interage com o objeto. Esta sequência de etapas resulta na conexão entre os dois, fortalecendo o vínculo entre eles e promovendo assim a comunicação.

A partir da definição dos conceitos chaves do produto, iniciou-se o processo de prototipação rápida, onde na Figura 2 apresenta-se o resultado.

Figura 2 - Protótipo em papel

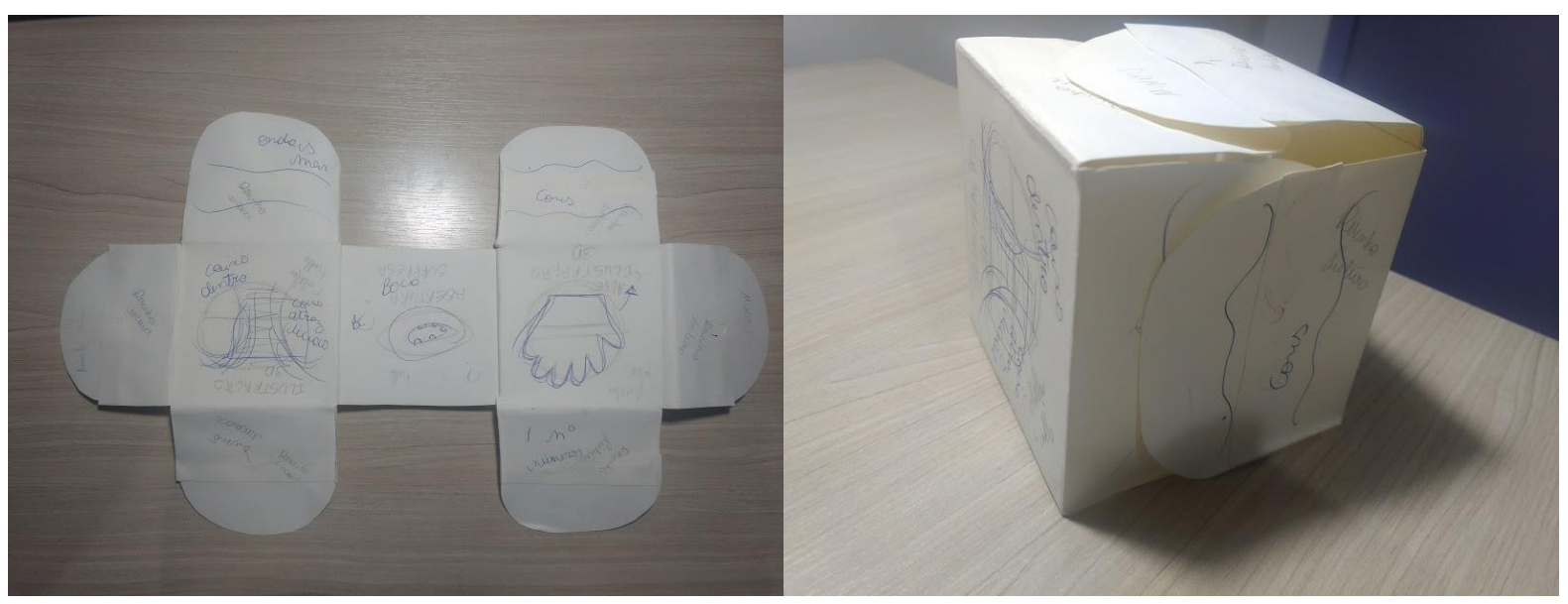

Fonte: as autoras (2017)

Com o desenvolvimento deste produto busca-se trabalhar a multissensorialidade da criança, que favorecem a psicomotricidade grossa, estimular a psicomotricidade fina, que favorecem a comunicação e linguagem, que trabalham as emoções, estimular a fala e conhecimento de mundo na criança, instruindo o responsável a auxiliar na comunicação e entrar no mundo da criança. 


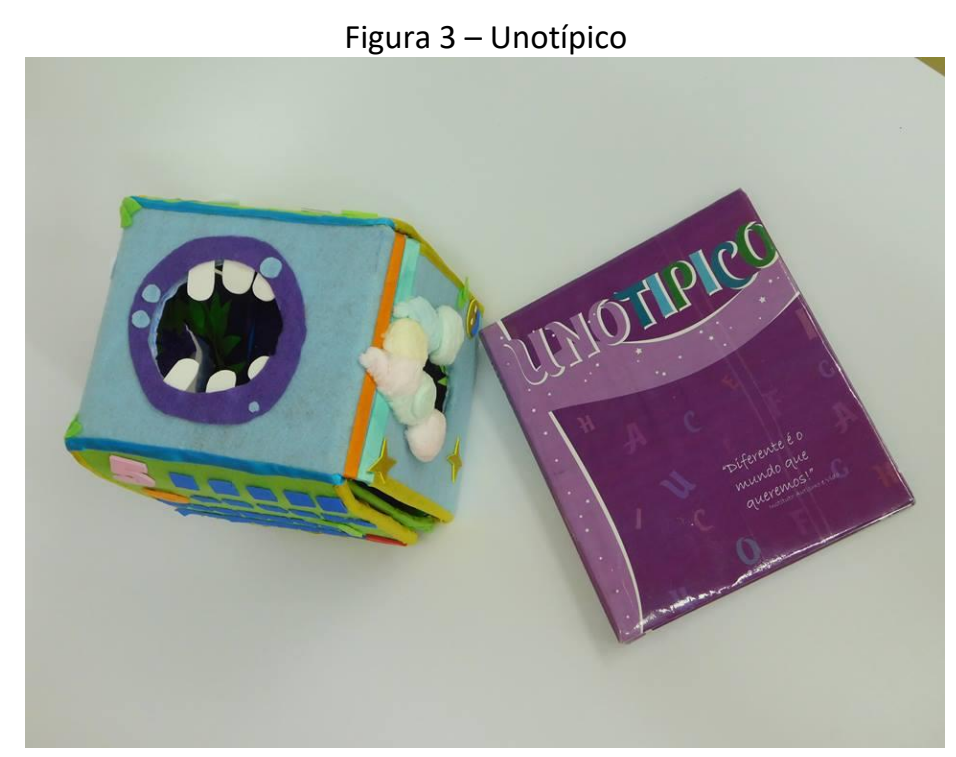

Fonte: as autoras (2017)

A caixa tem como função principal servir de suporte para objeto, e função secundária despertar curiosidade na criança, o livro tem função principal instruir o responsável na condução com a criança, função secundária diário/guia do desenvolvimento da criança. Os conceitos estéticos e simbólicos trabalhados foram a ludicidade, formato aconchegante, tema magia, interativo, inspirado em personagens que a criança tem identificação e cores atrativas.

\section{Figura 3 - Brinquedo}

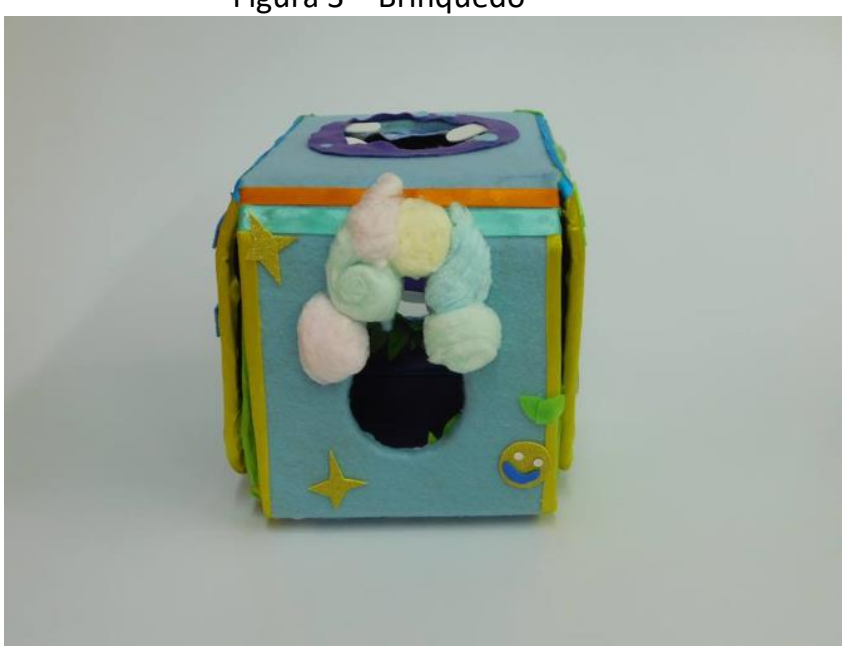

Fonte: as autoras (2017)

O produto desenvolvido contém um suporte (caixa surpresa, box surpresa, brinquedo) e um livro contendo instruções (diário, relatório de desenvolvimento). Ele se caracteriza pela criação de um brinquedo que tem como proposta de brincadeira colocar um objeto dentro de um suporte para despertar a curiosidade da criança, com objetivo de que os responsáveis interajam verbalmente (com entonação de voz) com a mesma, proporcionando um estímulo a comunicação. Podendo ainda integrar atividades relacionadas à fonoaudiologia e a psicopedagogia para facilitar o trabalho dos profissionais. 


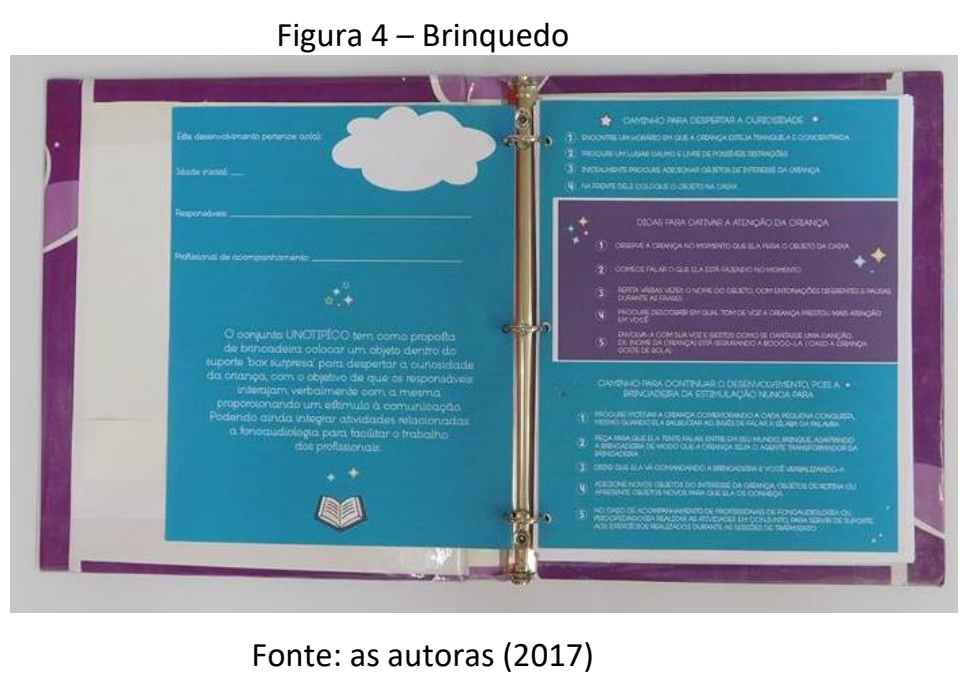

Juntamente com a caixa o produto acompanha um livro de dicas e instruções para utilização do brinquedo, onde mãe, responsáveis e demais profissionais podem trabalhar diversas atividades para estimular a comunicação da criança.

\section{Considerações Finais}

O projeto serviu para mostrar como o design pode auxiliar no desenvolvimento de brinquedos para crianças autistas, tendo em vista que esse público necessita de produtos que possam auxiliar nas suas atividades e necessidades diárias.

Por meio das metodologias de projeto propostas, se obteve uma solução de sucesso e que resolveu os problemas apontados, tendo como resultado um brinquedo inovador, atraente e que atende a necessidade encontrada no público alvo do projeto.

O foco do produto é estimular a comunicação e despertar a curiosidade da criança, com o objetivo de que os responsáveis interajam verbalmente com a mesma, proporcionando um vínculo afetivo entre eles, podendo ainda integrar atividades relacionadas a fonoaudiologia e psicopedagogia para facilitar o trabalho dos profissionais, ou seja, os mesmos podem adquiri-lo.

O projeto contribui para um melhor desenvolvimento na comunicação do indivíduo, sendo uma maneira prática de acompanhar o desenvolvimento da criança e uma forma dos responsáveis entrarem no mundo da mesma e criar empatia para com ela.

O produto desenvolvido intitulado Unotípico reúne os conceitos de "único" e "atípico" (que é termo utilizado para classificar pessoas com TEA). , que no seu conceito final tem embasamento no design e torna-se uma maneira única de ensinar e aprender.

Com esse projeto, aprendeu-se sobre a importância do designer como um solucionador de problemas. Seus conhecimentos, juntamente com outras áreas, contribuem desde significativamente para a melhoria da qualidade de vida, estímulos e desenvolvimento de crianças com espectro autista. 


\section{Referências}

AMERICAN PSYCHIATRIC ASSOCIATION. Diagnostic and Statistical Manual of Mental Disorders, Fifth Edition (DSM-V). Arlington, VA: American Psychiatric Association, 2013.

AUTISM SCIENCE FOUNDATION. In: Autism Science Foundation é uma organização sem fins lucrativos, 2017. Disponível em: <http://autismsciencefoundation.org/what-is-autism/autismdiagnosis/>. Acesso em: 18 setembro, 2017

AUTISMSPEAKS. Como o autismo é diagnosticado? In: Autismspeaks, 2017. Disponível em: < https://www.autismspeaks.org/what-autism/diagnosis/>. Acesso em: 22 setembro, 2017

BAXTER, Mike. Projeto de Produto: Guia prático para o design de novos produtos. ed. São Paulo: Blucher, 1998.

BROWN, Tim. Design Thinking: Uma metodologia poderosa par decretar o fim das velhas ideias. ed. Rio de Janeiro: Campus, 2010.

CENTER FOR UNIVERSAL DESIGN, Principles of Universal Design. Disponível em: http://www. ncsu.edu/ncsu/design/cud/about_ud/about_ud.htm. Acesso em: 5 de novembro, 2017.

FERRÉS, Magdalena Sofia Pérez. Design Inclusivo. Brasil: Todos Nós. 2005. Disponível em: https://www.maxwell.vrac.puc-rio.br/30055/30055_3.PDF. Acesso em 5 de novembro de 2017

KWANT, Fatima. Autismo e a comunicação verbal. In: Autimates, 2017. Disponível em: <http://webcache.googleusercontent.com/search?q=cache\%3Ahttp\%3A\%2F\%2Fwww.autimates.c om\%2Fautismo-e-comunicacao-verbal\%2F\&gws_rd=cr\&dcr=0\&ei=ovYjWqqLHcuWwAT74qog>. Acesso em: 18 de outubro, 2017

RUSSO, Dra. Fabiele. Comportamento sensorial no autismo: como trabalhar. In: Neuroconecta, 2017. Disponível em: <http://neuroconecta.com.br/comportamento-sensorial/>. Acesso em: 24 setembro, 2017

RUSSO, Dra. Fabiele. Escolha de brinquedos para crianças com TEA. In: Neuroconecta, 2017. Disponível em: < http://neuroconecta.com.br/graus-de-autismo-importante-saber/>. Acesso em: 02 outubro 2017

RUSSO, Dra. Fabiele. Fonoaudiologia e autismo: reduzindo dificuldades de linguagem e comunicação no TEA. In: Neuroconecta, 2017. Disponível em:

<http://neuroconecta.com.br/fonoaudiologia-e-autismo-reduzindo-dificuldades-de-linguagem-ecomunicacao-no-tea/>. Acesso em: 23 de setembro, 2017

RUSSO, Dra. Fabiele. Graus de Autismo - importante saber. In: Neuroconecta, 2017. Disponível em: < http://neuroconecta.com.br/graus-de-autismo-importante-saber/>. Acesso em: 22 de setembro, 2017

RUSSO, Dra. Fabiele. Sinais, sintomas e diagnóstico do TEA. In: Neuroconecta, 2017. Disponível em: <http://neuroconecta.com.br/sinais-sintomas-e-diagnostico-do-transtorno-do-espectro-doautismo/>. Acesso em: 18 de setembro, 2017

TARRÉS, Sara. Brinquedos adequados para crianças com autismo. In: Guia Infantil, 2015. Disponível em: <https://www.portaleducacao.com.br/conteudo/artigos/pedagogia/definicao-dostermos-brinquedo-brincadeira-e-jogo/35529>. Acesso em: 22 de setembro, 2017 
SILVA D. G.; PERANZONI, V. C. Autismo: um mundo a ser descoberto.08/2012. Disponível em: < http://www.efdeportes.com/efd171/autismo-um-mundo-a-ser- descoberto.htm > Acesso em: 8 de novembro 2017.

SIMÕES, Jorge Falcato; BISPO, Renato. Design Inclusivo: acessibilidade e usabilidade em produtos, serviços e ambientes. Manual de apoio às ações de formação do projeto de Design Inc. 2006. 